\title{
IMMUNOSUPPRESSION WITH CYCLOPHOSPHAMIDE DOES NOT PREVENT DEMYELINATION OR RESULT IN UNCONTROLLED VIRAL REPLICATION IN CORONAVIRUS SD INFECTED MICE
}

\author{
J.S. Burks, L. Jankovsky, P.A. Licari, \\ I.T. McNally and M.C. Kemp \\ Center for Neurological Diseases/Rocky Mountain Multiple \\ Sclerosis Center, University of Colorado School of \\ Medicine, Veterans Administration Medical Center \\ Denver, Colorado, U.S.A.
}

Coronavirus SD following intracerebral inoculation has been shown to precipitate demyelination in the brains and spinal cords of weanling mice (1). Demyelination occurs at a time when virus cannot be isolated and some areas of demyelination are associated with a perivascular inflammatory response. Also, IgG is present in demyelinated areas. Since demyelination may be immunologically mediated, this study evaluates the effect of immunosuppression with cyclophosphamide (CY) on demyelination and viral replication.

Coronavirus SD was inoculated intracerebrally into 3 - 4 week old $\mathrm{C} 57 \mathrm{Bl} / 6 \mathrm{~J}$ mice at $10^{4} \mathrm{pfu} / .03 \mathrm{ml}$. Half of the mice were immunosuppressed with CY $(200 \mathrm{mg} / \mathrm{kg})$ at day $1,5,9,13$, and 17 postinoculation (PI). Mice were sacrificed at days 5, 12, and $20 \mathrm{PI}$.

With the non-immunosuppressed mice, $27 \%$ exhibited neurological signs on days 4 through 7 , with $100 \%$ recovery by day 8 . of the immunosuppressed mice, $90 \%$ exhibited no clinical signs on days 4 through 12 with a mortality rate of $27 \%$.

The mice treated with CY had no serum antibody to coronavirus SD by an EIA assay, while the non-treated mice had a mean titer of $1: 2560$ on days 12 and 20 PI. Spleens and thymuses of CY treated animals were markedly reduced in size. Histologically, thymic cortices were hypocellular and splenic white pulp was depleted.

Virus concentrations in brain, dethermined by a plaque assay, reached a maximum of $10^{4} \mathrm{pfu} / \mathrm{ml}$ and $10^{3} \mathrm{pfu} / \mathrm{ml}$ in $\mathrm{CY}$ treated and untreated mice, respectively, at day 5 PI. By day 12 PI, virus 
could not be isolated from mice in either group. The mechanism(s) by which SD was eliminated from the mice by day 12 PI in the CY treated mice is unknown. Viral antigen was detected by autoradiography in the brain and spinal cord at days 12 and 20 PI in both groups. Bound IgG, which was abundant in demyelinated areas of non-immunosuppressed mice, was absent in CY treated mice.

Coronavirus SD induced demyelination was not prevented by CY treatment. Small focal subpial and large deep perivascular demyelinating lesions were produced in both groups. Although macrophage infiltration remained, perivascular lymphocyte accumulations were not present in the CY treated mice (Fig. 1).

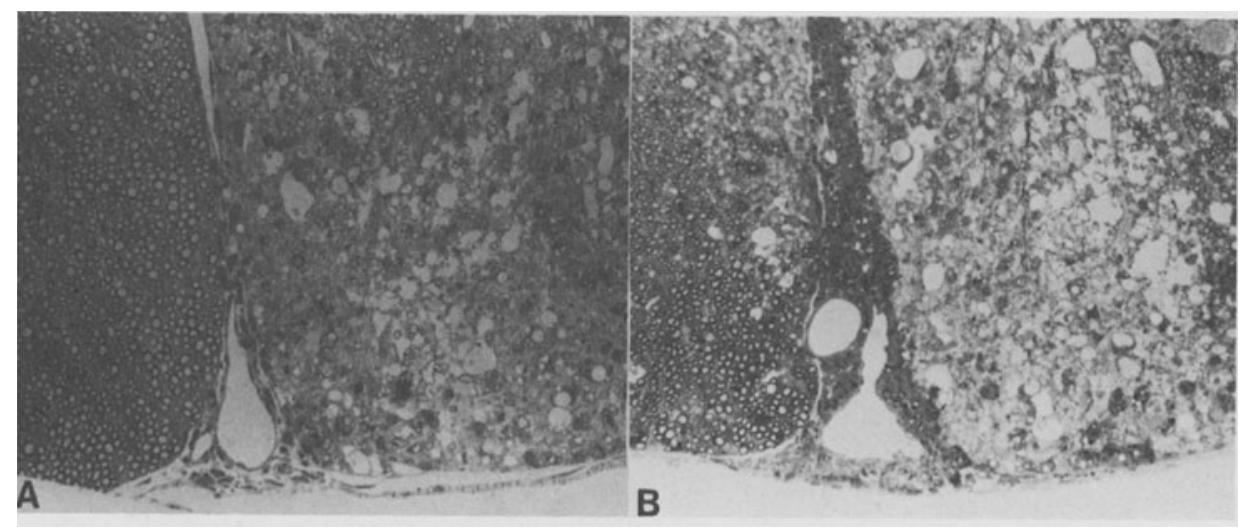

Fig. 1: Demyelinated lesions in the spinal cord of SD infected mice were similar in size and location in CY treated (A) and untreated mice (B). However, CY treatment prevented the perivascular accumulation of iymphocytes and plasma cells commonly seen in demyelinating lesions; $640 \mathrm{X}$.

\section{REFERENCES}

1. Mendleman, P.M., L.D. Jankovsky, R.S. Murray, P. Licari, B.L. DeVald, J.C. Gerdes \& J.S. Burks, 1983. Pathogenesis of Coronavirus SD in Mice. I Prominent Demyelination in the Absence of Infectious Virus Production. Arch. Neurol. In Press.

2. Gerdes, J.C., I. McNally, L. Hileman, J.S. Burks, 1982 . Autoradiographic Detection of $\mathrm{IgG}$ and Viral Antigens. J. Immunol. Meth. 54:191-202.

This work was supported by the Kroc Foundation and the Veterans Administration. 